\title{
Coral community changes in response to a high sedimentation event: A case study in southern Hainan Island
}

\author{
LI XiuBao ${ }^{1,2}$, HUANG Hui ${ }^{1,2^{*}}$, LIAN JianSheng ${ }^{1}$, YANG JianHui ${ }^{1}$, YE Cheng ${ }^{1}$, \\ CHEN YongQiang ${ }^{1} \&$ HUANG LiangMin ${ }^{1}$ \\ ${ }^{1}$ Key Laboratory of Marine Bio-resources Sustainable Utilization, South China Sea Institute of Oceanology, Chinese Academy of Sciences, \\ Guangzhou 510301, China; \\ ${ }^{2}$ Tropical Marine Biological Research Station in Hainan, Chinese Academy of Sciences, Sanya 572000, China
}

Received September 5, 2012; accepted November 2, 2012; published online December 24, 2012

\begin{abstract}
A high sedimentation event caused by dredging and dumping of sediment was recorded on Xiaodonghai Reef in Yulin Bay, southern Hainan Island, China. Significantly high sedimentation and constant light shading were observed during the sediment dumping event (SD Event). Using long-term video transects, we quantified coral community changes and responses to the SD Event between 2008 and 2010. The SD Event caused severe coral mortality on Xiaodonghai Reef at a depth of $6 \mathrm{~m}$, while corals at $3 \mathrm{~m}$ were less affected. Total live coral cover at $6 \mathrm{~m}$ decreased from 54.3\% to 14.8\%, and Diploastrea heliopora replaced Galaxea fascicularis as the dominant coral species at 6 and $9 \mathrm{~m}$. The density of juvenile corals also declined after the SD Event, especially for the genera Galaxea and Platygyra. However, the density of juvenile Porites and Pocillopora spp. slightly increased. Monitoring for 11 months after the SD Event indicated no recovery of coral communities on Xiaodonghai Reef. Long-term video transect data also revealed that mean live coral cover dramatically declined, from $30.5 \%$ in 2008 to $9 \%$ in 2010 , while the dominant corals in Yulin Bay shifted to more tolerant coral species, such as massive Porites spp. and D. heliopora. The rapid coral community degradation in Yulin Bay between 2008 and 2010 was probably caused by high sediment deposition resulting from intensive dredging and land-clearing activities. These results highlight the necessity for an integrated watershed management to control sediment deposition on near-shore coral reefs.
\end{abstract}

coral community composition, dredging, sediment accumulation rate, recovery, Hainan Island, juvenile coral

Citation: $\quad$ Li X B, Huang H, Lian J S, et al. Coral community changes in response to a high sedimentation event: A case study in southern Hainan Island. Chin Sci Bull, 2013, 58: 1028-1037, doi: 10.1007/s11434-012-5601-5

Scleractinian corals, as the major reef-building organisms, play a key role in maintaining the stability and function of coral reef ecosystems [1]. However, by 2008 the world had effectively lost $19 \%$ of the original area of coral reefs; $15 \%$ are seriously threatened with loss within the next 10-20 years; and $20 \%$ are under threat of loss in 20-40 years [2]. Of the 704 scleractinian coral species that could be assigned conservation status, $32.8 \%$ are in categories with elevated risk of extinction [3]. Scleractinian coral communities are sensitive to many disturbances, such as thermal stress [4,5], ocean acidification [6], outbreaks of crown-of-thorns star-

*Corresponding author (email: coralreef@scsio.ac.cn) fish (COTS; Acanthaster planci) [7,8], overfishing [9], typhoon damage [9] and terrestrial pollution [10]. Coral bleaching and ocean acidification resulting from climate change have become the main threats to coral reef on a global scale, whereas on regional scales, terrestrial pollution (especially heavy sedimentation) has become the main threat to inshore coral reefs $[6,11,12]$. Heavy sedimentation may result in light shading, sediment abrasion on the coral surface, smothering of coral tissues and may eventually lead to its death $[13,14]$. Heavy sedimentation results in fewer coral species, less live coral, lower coral growth rates, reduced coral recruitment, decreased calcification, decreased net productivity of corals, and slower rates of reef accretion 
[11,15-17].

Dredging is an extreme event causing high sedimentation and is associated with construction of hotels, runways, roads, harbors, and military installations, as well as with beach replenishment $[17,18]$. It has been considered as a high-risk event because of its likely deleterious effects to the marine environment and is one of the biggest potential sources of reef degradation resulting from human activities, being an especially severe risk in developing countries [17,19]. Maragos estimated that about $80 \%$ of the corals in the lagoon in Kaneohe Bay, Hawaii, died as a result of dredging and accompanying increased sedimentation [20]. Moreover, Uchino observed significant degradation of coral communities in the same area 60 years later [21]. A 30\% reduction in live coral cover and significant decline in species diversity were observed after a 9-month dredging operation in Phuket [22]. Live coral cover decreased by $40 \%$ and partial coral death significantly increased during a dredging operation in Hong Kong [23]. Although the detrimental effects of dredging on coral reefs have been reviewed [17,18,22,24], the impact of dredging on corals and coral reef ecosystems is complex and far from fully understood [18]. Few studies have presented detailed and quantitative data on coral community changes before and after a dredging event [22]. To date, limited data exist for accurate assessment of the responsive mechanism, threshold levels and the recovery process at the coral community level (especially for juvenile corals) to acute heavy sedimentation during a dredging or sediment dumping event.

An acute sedimentation event was recorded on Xiaodonghai Reef during September-November 2009 due to dredging and dumping of sediment in Yulin Bay, southern Hainan Island. This provided us with a study site for the investigation of coral community changes before and after a high sedimentation event. We discuss the responses, threshold levels and recovery of the coral communities on Xiaodonghai Reef. We also investigated coral community changes between 2008 and 2010 in Yulin Bay and discuss the main causes.

\section{Materials and methods}

\subsection{Study sites}

Yulin Bay is located downstream of Hongsha Port, which is an important marine cage culture area and one of the most important stopover harbors in Sanya City. Yulin Bay is therefore severely polluted by sewage from Hongsha Port and the Liudao city sewage outlet, and the environmental status was severely degraded in the mouth areas of Yulin Bay $[25,26]$. Recent surveys established the ranges of environment variables on the coral reefs of Yulin Bay. These were $19.9-31.7^{\circ} \mathrm{C}$ for seawater temperature at $3 \mathrm{~m}$ depth during 2008-2010 (Figure 1); 33-33.1 psu for salinity; 6.8-7.0 $\mathrm{mg} \mathrm{L}^{-1}$ for dissolved oxygen; 3.2-8.5 FTU for

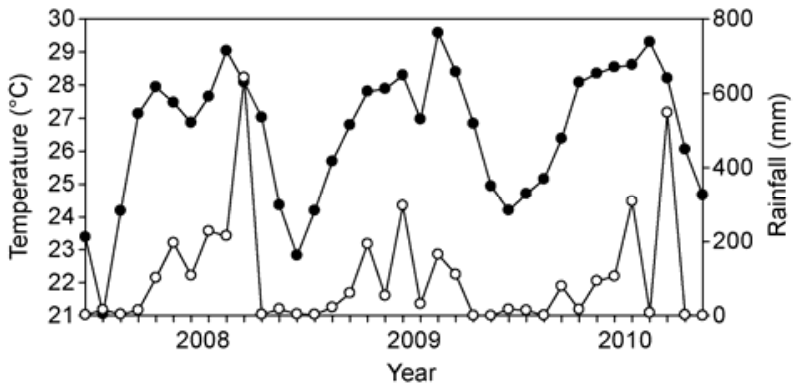

Figure 1 Monthly mean seawater temperatures in ${ }^{\circ} \mathrm{C}(\bullet)$ at $3 \mathrm{~m}$ depth on Xiaodonghai Reef (YL4), and monthly mean rainfall in $\mathrm{mm}(\mathrm{O})$ in Luhuitou during 2008-2010.

turbidity; 3.1-6.3 mg L ${ }^{-1}$ for suspended solids; and $0.7-1.7$ $\mu \mathrm{g} \mathrm{L}{ }^{-1}$ for chlorophyll $a$ in the rainy seasons [27]

The coral reefs of Yulin Bay are an important component of the Sanya National Natural Coral Reef Reserve. In total, 51 scleractinian coral species and abundant coral communities have been recorded in Yulin Bay in the past $[28,29]$. Previous studies found that coral communities in the western part of the bay (e.g. Xiaodonghai and Dadonghai Reefs) were mainly composed of Acropora spp., with total live coral cover of more than $60 \%$ on Xiaodonghai Reef and 30\%-40\% on Dadonghai Reef in 1978 [29]. Both reefs have been impacted by terrestrial inputs and human activities, such as over-fishing, explosive-fishing and diving tourism [30,31]. The eastern part of Yulin Bay is mostly mountainous and sparsely populated. Therefore, in that region, coral communities have been less impacted by human activities.

However, because of the implementation of near-shore military installations, intensive land clearing, dredging, and harbor and breakwater construction have been conducted in the eastern part of Yulin Bay since 2009 (Figures 2 and 3). The dredged sediment from four dredging ships was dumped randomly in nearby deep water during September-November 2009. The exact volume of dredged sediment is not known, as this was a military project. The sediment dumping event (the SD Event) occurred in the wet season, with the total precipitation being $275.6 \mathrm{~mm}$ (Figure 1), and the dominant wind direction ranged from North-East to South-West during that time. Yulin Bay experiences irregular daily tides and is apparently controlled by tidal currents, with a speed of less than $20 \mathrm{~cm} \mathrm{~s}^{-1}$. The direction of the tidal current is North-East during flood tides and South-West during ebb tides and rotatively reciprocating [26,32]. Some of the dumped sediment was captured, recycled near the mouth areas of Yulin Bay and then transported to Xiaodonghai and Dadonghai Reefs during flood tides. This was confirmed by a tracer particle study that showed that pollutants (e.g. suspended solid and nutrients) can be easily transported from the mouth areas of Yulin Bay to Xiaodonghai and Dadonghai Reefs [33]. High sedimentation and constant light shading was recorded on Xiaodonghai Reef (YL4) during the SD Event. The high sedimentation was also confirmed by 


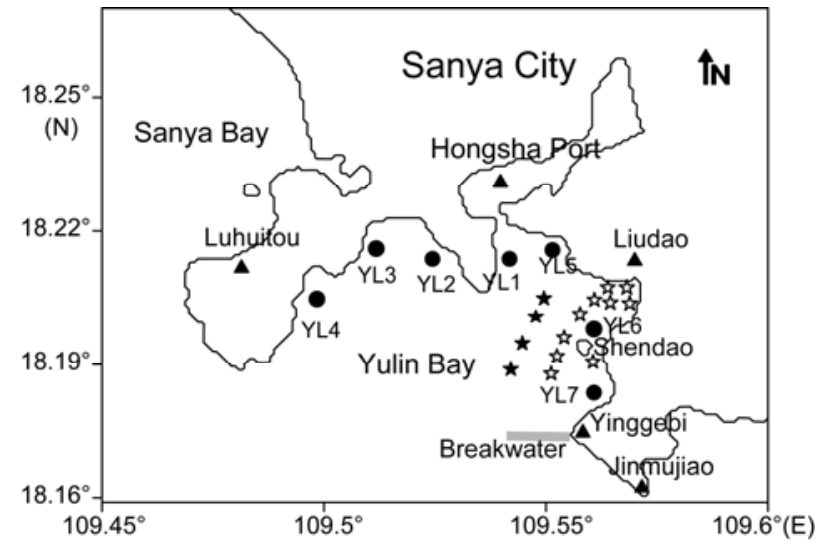

Figure 2 Study sites in Yulin Bay (YL1-YL7) are indicated as closed circles. Site YL4 is located on Xiaodonghai Reef while YL2 and YL3 are located on Dadonghai Reef. Open five-pointed stars indicate dredging sites and closed five-pointed stars indicate sediment dumping sites during the sediment dumping event. A breakwater was also built in Yinggebi during the event.

the general manager of the Sanya Global Diving Company in Xiaodonghai (Fu Wang, personal communication), with frequent suspension of diving projects during this period owing to high seawater turbidity.

\subsection{Environmental variables}

Four sets of sediment traps, with an inner diameter of $4.4 \mathrm{~cm}$ and height of $16 \mathrm{~cm}$, placed $50 \mathrm{~cm}$ above the substratum, were used to monitor the sediment accumulation rate along the long-term transects at the depths of 3, 6 and $9 \mathrm{~m}$ on Xiaodonghai Reef (YL4). The collected particles were washed with distilled water, sieved, and then dried in an oven at $60^{\circ} \mathrm{C}$ for $48 \mathrm{~h}$. Sediment accumulation rates were obtained by weighing the dried sediments $( \pm 0.10 \mathrm{mg})$ and then dividing by the collection time and the mouth area of collection tubes. Particle size was determined using a laser particle size analyzer (Mastersizer 2000, Malvern Instruments Ltd., Worcestershire, UK). The polyvinyl chloride (PVC) traps were replaced using SCUBA in July and October 2009.

Seawater temperature was recorded at $3 \mathrm{~m}$ depth on Xiaodonghai Reef using a HOBO water temperature logger (model U22-001, Onset, USA). Rainfall data were obtained from the weather station at Hainan Tropical Marine Biology Research Station, Chinese Academy of Sciences. A light attenuation coefficient $(K)$ was used to indicate the light intensity. $K$ was calculated from Secchi disk observations by the relationship $K=1.5 / d$ where $d$ is the depth in meters at which the disk disappears from view [34]. Measurements were made before, during and after the SD Event on Xiaodonghai Reef. Density of the snails Drupella fragum and Drupella rugosa (Drupella spp.), which predate on corals, was determined by the same method as for determination of the density of juvenile corals (section 1.3). Snail density on
Xiaodonghai Reef was investigated three times, in August 2008, July 2010 and November 2010.

\subsection{Coral communities}

In April 2007, $60 \mathrm{~m}$ transects were deployed at 3, 6 and $9 \mathrm{~m}$ to allow measurement of seasonal variations in the coral communities on Xiaodonghai Reef (YL4). At seasonal intervals, divers swam slowly along each $60 \mathrm{~m}$ transect line for $15 \mathrm{~min}$, recording with a video and the linear point intercept (LPI) method was used to estimate the coverage of coral communities at $10 \mathrm{~cm}$ intervals from the videos [35]. Scleractinian corals were indentified to species level. This data allowed us to investigate coral community changes before and after the SD Event on Xiaodonghai Reef. Data were collected on six occasions between December 2008 and November 2010.

Juvenile coral density was assessed along each of the $60 \mathrm{~m}$ long-term transects on Xiaodonghai Reef (YL4) by the visual census method [36]. At each depth, juvenile corals $(0.4 \mathrm{~cm} \leqslant$ diameter $\leqslant 5 \mathrm{~cm})$ were carefully counted in at least 32 random quadrats $(0.5 \mathrm{~m} \times 0.5 \mathrm{~m})$ along each $60 \mathrm{~m}$ transect. The majority of juvenile corals were identified to genus level, with some allocated to the category 'Other' if they were not identified to genus level. Juvenile corals of the genus Porites were mainly massive. Determination of juvenile coral density was carried out four times, in August 2008, March 2010, July 2010 and November 2010.

To assess the potential effect of dredging activities on coral communities in Yulin Bay, a baseline investigation was conducted in December 2008, before the building of near-shore military installations commenced (Figure 2). In total, nine $50 \mathrm{~m}$ transects were deployed at 6 sites (YL1, YL3-YL7) in Yulin Bay, parallel to the shoreline. At most sites (except YL4 at 3, 6 and $9 \mathrm{~m}$, and YL7 at 3 and $6 \mathrm{~m}$ ) only the $3 \mathrm{~m}$ transect was measured before the SD Event. To assess coral community changes after the SD Event, a total of fifteen $60 \mathrm{~m}$ transects were deployed at 6 sites (YL1-YL4, YL6-YL7) in November 2010, again mostly at 2 or $3 \mathrm{~m}$ depths at each site ( 8 of the 15 transects were the same as in the baseline investigation). Coverage of coral communities was estimated using the LPI method, based on 500 points along each $50 \mathrm{~m}$ transect as described above.

\subsection{Statistical analysis}

Data were tested for normality of assumptions using the Kolmogorov-Smirnov test and for homogeneity of variance using Levene's test. Independent-samples $t$-test or one-way ANOVA was used to test the difference between environment variables. Regression analysis was used to test the changes of live coral coverage on Xiaodonghai Reef between 2008 and 2010. Statistical analysis was carried out using a statistical package (SPSS 13.0 for Windows; SPSS Inc., Chicago, IL, USA). 

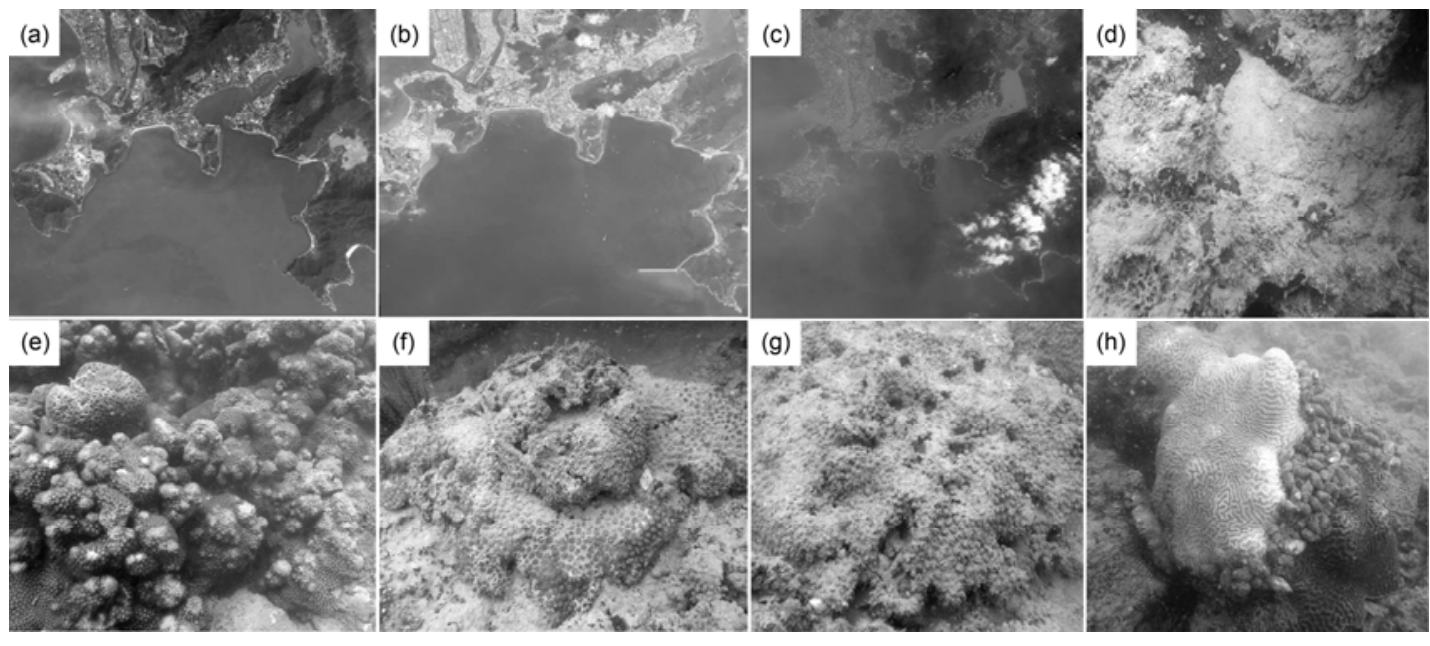

Figure 3 Satellite images and coral communities of Yulin Bay. Satellite images of Yulin Bay on 11 January 2009 (a) and 1 June 2010 (b) indicated intensive land clearing and ocean projects during the period. (c) Satellite image of Yulin Bay on 19 October, 2010 showed turbid plumes and strong soil erosion through rainwater due to land clearing. (d) Fine sediments on reefs induced partial coral death on Shendao Reef (YL6) (29 November 2010). (e) Live colonies of coral Galaxea fascicularis before the sediment dumping event on Xiaodonghai Reef (YL4). (f) and (g) Partial death and dead colonies of coral G. fascicularis caused by fine sediment deposition after the sediment dumping event on Xiaodonghai Reef (YL4). (h) Predation by Drupella spp. snails on Platygyra sp. after the sediment dumping event on Xiaodonghai Reef (YL4).

\section{Results}

\subsection{Environmental variables and coral community changes between 2008 and 2010 on Xiaodonghai Reef}

High sediment accumulation rates and constant light shad-
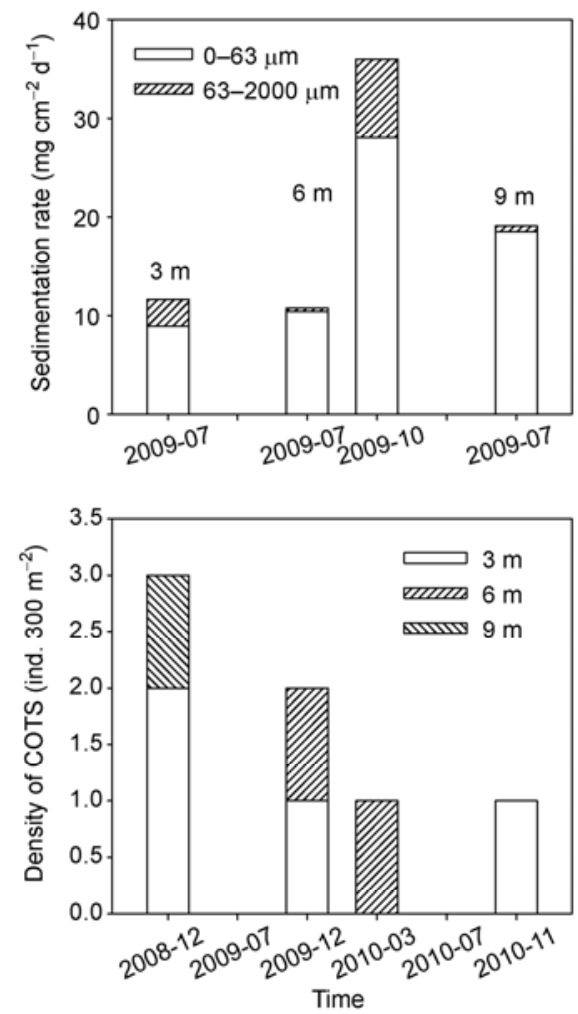

ing were recorded on Xiaodonghai Reef during the SD Event (Figure 4). The sediment accumulation rate of 36.0 $\mathrm{mg} \mathrm{cm} \mathrm{cm}^{-1}$, measured during the SD Event, was significantly higher than the value measured before the SD Event ( $t$-test, $P<0.001)$. The light attenuation coefficient during
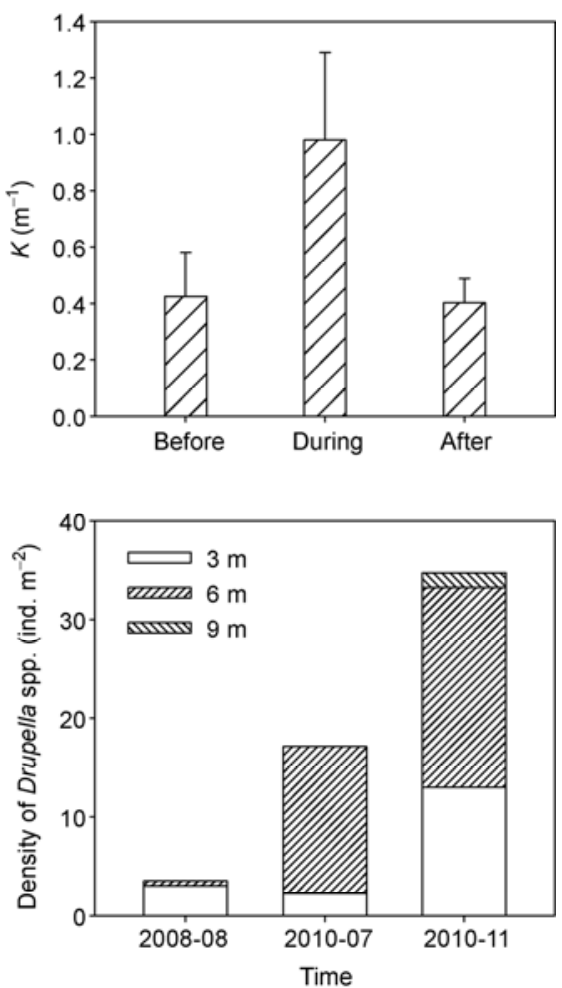

Figure 4 Temporal variation in sediment accumulation rate, light attenuation coefficient $(K)$ and densities of Acanthaster planci (COTS) and snails (Drupella spp.) on Xiaodonghai Reef (YL4) between 2008 and 2010. The light attenuation coefficient (mean \pm SD; $n=3$ ) was measured before, during and after the sediment dumping event. Depths: $3 \mathrm{~m}, 6 \mathrm{~m}$ and $9 \mathrm{~m}$. Particles size of the collected sediment: $0-63 \mu \mathrm{m}$ and $63-2000 \mu \mathrm{m}$. 
the SD Event was higher than the values seen before and after the SD Event. The mean density of snails (Drupella spp.) increased from 1.2 ind. $\mathrm{m}^{-2}$ before to 8.6 ind. $\mathrm{m}^{-2}$ after the SD Event.

Mass coral community degradation was observed on Xiaodonghai Reef in the time period 2008-2010 (Figures 5 and 6). At $3 \mathrm{~m}$, live coral cover apparently declined (-9.5\%) in response to the high sedimentation resulting from the SD Event. Percentage composition of Galaxea fascicularis decreased while that of the genera Montipora, Platygyra, Goniastrea and Favites increased. However, 3 months after the SD Event (March 2010) mean live coral cover had recovered to the original level $(9.3 \%)$. Subsequent monitoring indicated that the coral community was further degraded and declined to the level after the SD Event (December 2009) as a result of disturbance of Typhoon Conson and an outbreak of the predatory snail Drupella spp., which intensively predated on stressed coral colonies. However, coral community composition was not changed after the SD Event.

At $6 \mathrm{~m}$, live coral cover sharply declined $(-39.5 \%)$ in response to the SD Event. Subsequent monitoring for 11 months after the SD Event indicated that the coral community further declined because of disturbance by Typhoon Conson and an outbreak of the snail Drupella spp. The snails primarily predated on dominant coral $G$. fascicularis. Therefore, the percentage composition of $G$. fascicularis decreased sharply from $94.8 \%$ to 0 , while that of Diploastrea heliopora increased from 0 to $63.6 \%$. Regression analysis demonstrated that coverage of total live coral, $G$. fascicularis, Porites spp. and Lobophyllia hemprichii significantly declined between 2008 and $2010(P=0.013,0.022$, 0.038 and 0.006 , respectively).

At $9 \mathrm{~m}$, a decline in live coral cover of $8.3 \%$ was recorded in July 2009 as a result of seasonal high sedimentation (Figure 5) while coral community composition did not change (Figure 6(c)). The SD Event had little impact on live coral cover, but produced great changes in coral composition. For example, the percentage composition of G. fascicularis notably declined while that of $D$. heliopora notably rose after the SD Event. Few changes in the coral community were recorded during subsequent monitoring. Regression analysis indicated that coverage of $G$. fascicularis significantly decreased between 2008 and $2010(P=0.027)$.

The mean density of juvenile corals was 20.2 ind. $\mathrm{m}^{-2}$ in 2008 and declined sharply to 6.4 ind. $\mathrm{m}^{-2}$ after the SD Event (Figure 7). Juvenile coral composition also changed markedly after the SD Event. Juvenile coral density and percentage composition of Porites at $6 \mathrm{~m}$ and $9 \mathrm{~m}$ increased while for other coral taxa these same parameters decreased, notably for Galaxea and Platygyra.

\subsection{Coral community changes in Yulin Bay between 2008 and 2010}

In 2008, mean live coral cover in Yulin Bay was 30.5\%,

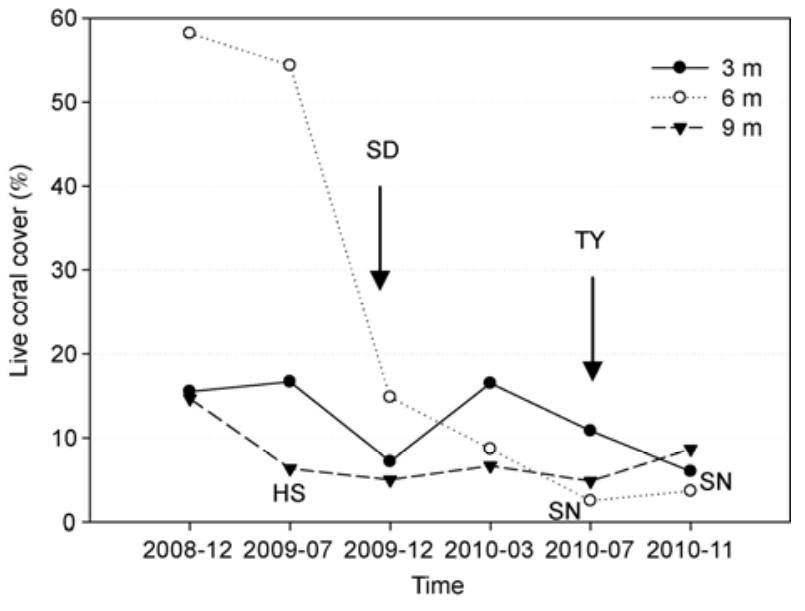

Figure 5 Temporal variation in live coral cover at the depths of $3 \mathrm{~m}, 6 \mathrm{~m}$ and $9 \mathrm{~m}$ on Xiaodonghai Reef (YL4) between 2008 and 2010. HS, Seasonal high sedimentation; SD, the sediment dumping event; SN, outbreak of the predatory snail Drupella spp.; TY: Typhoon Conson landed in Sanya on 16 July, 2010 (source: http://weather.unisys.com/hurricane/index.php).

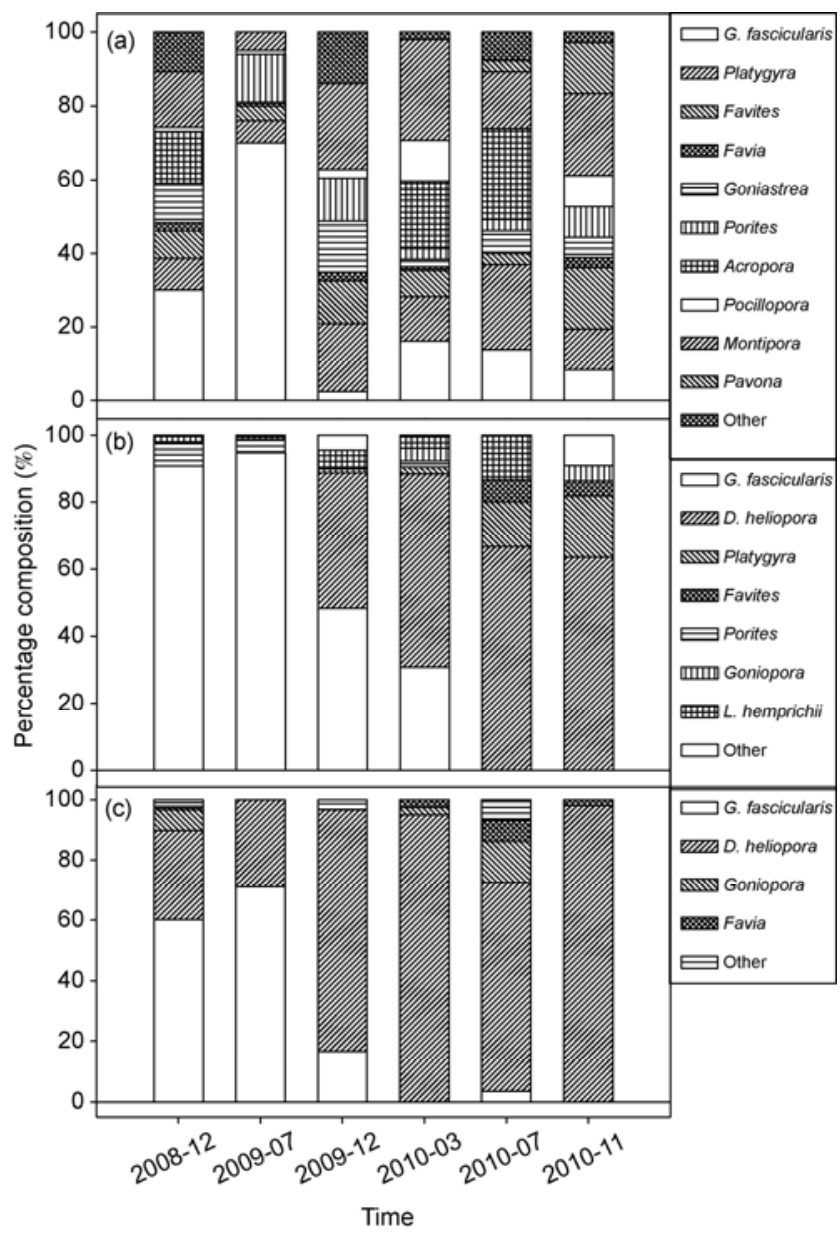

Figure 6 Percentage composition changes in the coral community on Xiaodonghai Reef (YL4) between 2008 and 2010. Depths: (a) 3 m; (b) 6 m; (c) 9 m.

ranging from $7 \%$ to $58.2 \%$ (Figure 8). In 2010, this figure was $9.0 \%$, ranging from $0.3 \%$ to $22 \%$. Based on video of 


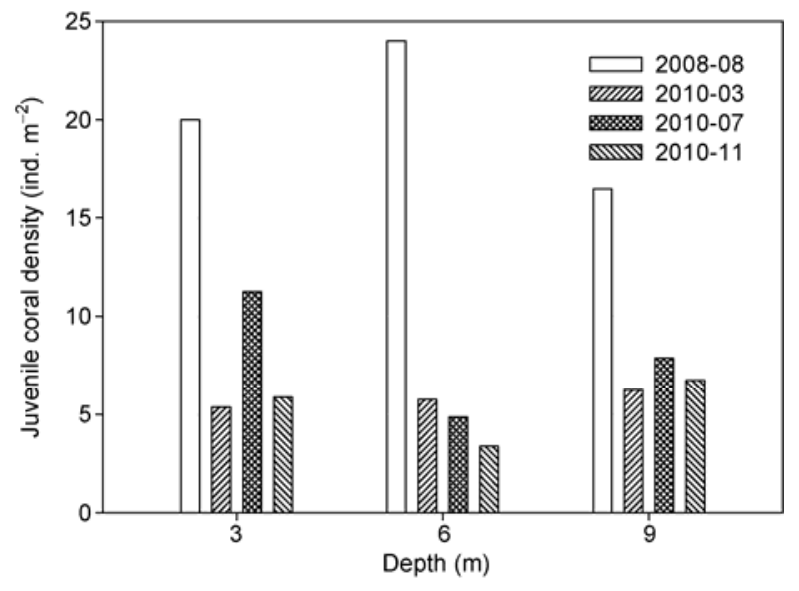

Figure 7 Temporal variation in juvenile coral density between 2008 and 2010 on Xiaodonghai Reef (YL4).

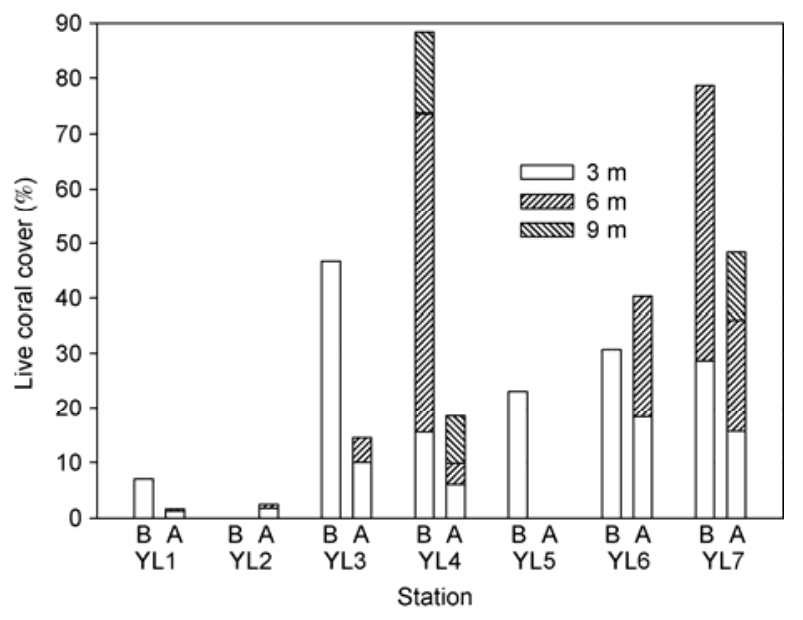

Figure 8 Live coral cover in Yulin Bay before (B, December 2008) and after (A, November 2010) the sediment dumping event. Most stations, except YL4 and YL7, were investigated at only one depth $(3 \mathrm{~m})$ before the sediment dumping event. No data were available for YL2 before the sediment dumping event or for YL5 after the sediment dumping event.

the same eight transects analyzed in 2008 and 2010, mean live coral cover declined sharply, from $31.4 \%$ in 2008 to $10.5 \%$ in 2010 ( $t$-test, $P=0.012$ ). Mean live coral cover thus decreased by $20.9 \%$ and the degradation rate reached $66.6 \%$. The cover of G. fascicularis and branching Porites spp. decreased while that of massive Porites spp. and D. heliopora increased (Table 1). This suggested that the coral community in Yulin Bay shifted to more tolerant coral species. By 2010, massive Porites spp. had become the dominant taxon, accounting for $40.5 \%$ of coral cover.

\section{Discussion}

\subsection{Responses and threshold levels of coral communities on Xiaodonghai Reef following a sediment dumping event}

Since March 2009, predation by the corallivorous snail
Table 1 Percentage composition of the coral community in Yulin Bay in 2008 and $2010^{\text {a) }}$

\begin{tabular}{lccc}
\hline \multicolumn{1}{c}{ Coral genera } & $2008-12$ & $2010-11$ & Change \\
\hline Porites & 34.7 & 45.4 & +10.7 \\
(Massive/branching) & $(19.8 / 15.0)$ & $(40.5 / 5.0)$ & $(+20.7 /-10.0)$ \\
Galaxea fascicularis & 32.1 & 2.0 & -30.1 \\
Diploastrea heliopora & 2.9 & 14.1 & +11.2 \\
Acropora & 1.1 & 0.4 & -0.7 \\
Montipora & 12.1 & 8.9 & -3.2 \\
Pocillopora & 1.8 & 0.6 & -1.2 \\
Goniopora & 2.0 & 7.5 & +5.5 \\
Platygyra & 2.1 & 3.4 & +1.3 \\
Favia & 0.9 & 6.9 & +6.0 \\
Favites & 1.5 & 4.0 & +2.5 \\
Goniastrea & 2.5 & 0.8 & -1.7 \\
Other & 6.3 & 6.0 & -0.3 \\
\hline a) Above & & &
\end{tabular}

a) Above data were calculated from video of the same 8 transects (i.e. $50-60 \mathrm{~m})$.

Drupella spp. has been found to cause partial death of some colonies at $6 \mathrm{~m}$ depth on Xiaodonghai Reef. However, snail predation has not resulted in a significant decline in live coral cover. Thus, mass coral community degradation after the sediment dumping event (SD Event) on Xiaodonghai Reef appeared to be caused mainly by the high sedimentation resulting from the SD Event, although snail predation on coral colonies may play a secondary role in the mass coral community degradation.

The response of coral communities on Xiaodonghai Reef to the SD Event differed depending on distribution depth and composition. The coral community at $3 \mathrm{~m}$ suffered less impact from the SD Event than that in deeper water (Figures 5 and 6). This suggests that the synergistic effect of high sedimentation and constant light shading in deep water has a more detrimental effect on coral communities than high sedimentation in shallow water [11]. Coral composition at 6 and $9 \mathrm{~m}$ was significantly changed after the SD Event. The dominant coral species shifted from $G$. fascicularis to $D$. heliopora in a relatively short time (5 months). A rapid shift in dominant coral species was also observed in New Caledonia following cyclone disturbance [37]. These results suggest that high sedimentation and light shading not only impacts total live coral cover, but also selectively removes some sensitive species and ultimately results in changes in the coral composition [15].

In this study, the dominant corals $G$. fascicularis and $D$. heliopora showed different sensitivity to the combined effects of high sedimentation and constant light shading during the SD Event. This difference was probably determined by their morphology. G. fascicularis is a sub-massive species and long-term light shading (e.g. $>1$ month) caused by turbid plumes would significantly disturb the energy budget 
of this coral [14]. With the rejection efficiency of the coral significantly reduced due to energy deficiency, silts particles could then easily deposit on the concave and flat surfaces, causing tissue death through smothering. D. heliopora is a massive species, and a strong, active sediment rejector: the secreted mucus containing the sediment could be washed away from colonies by slight water movement $[14,38]$. Large-polyped corals such as D. heliopora, with greater efficiency in zooplankton capture, would be expected to be more resistant to shading and have higher active-rejection capability for deposited sediment [38-40].

Previous studies have found the coral G. fascicularis, which has large calices and long tentacles, to be one of the most efficient sediment rejecters during the first few hours of sediment stress [14] and showed relatively high tolerance to sedimentation $[12,14,41,42]$. However, these studies only qualitatively evaluated the tolerance of $G$. fascicularis to high sedimentation and none referred to the threshold of the species to sedimentation. In this study, coverage of $G$. fascicularis slightly decreased at the sediment accumulation rate of $19.1 \mathrm{mg} \mathrm{cm}^{-2} \mathrm{~d}^{-1}$ and significantly decreased at $36 \mathrm{mg} \mathrm{cm}^{-2} \mathrm{~d}^{-1}$. However, coverage of G. fascicularis remained constant when the sediment accumulation rate was close to $10 \mathrm{mg} \mathrm{cm}^{-2} \mathrm{~d}^{-1}$. Therefore, the threshold of $G$. fascicularis on Xiaodonghai Reef appears to be higher than $10 \mathrm{mg} \mathrm{cm}^{-2} \mathrm{~d}^{-1}[17,43]$ and close to $19.1 \mathrm{mg} \mathrm{cm}^{-2} \mathrm{~d}^{-1}$. When the sediment accumulation rate reached $36 \mathrm{mg} \mathrm{cm}^{-2} \mathrm{~d}^{-1}$, coverage of $D$. heliopora increased and we therefore concluded that the threshold of $D$. heliopora was higher than $36 \mathrm{mg} \mathrm{cm}^{-2} \mathrm{~d}^{-1}$.

This study was the first to evaluate changes in juvenile coral density and composition during a high sedimentation event. A significant decline in both density and percentage composition of most juvenile corals was recorded. This confirmed the hypothesis that juvenile corals are more sensitive to high sedimentation than adult coral colonies [44]. However, the density of juvenile Pocillopora increased slightly from 1 to 1.5 ind. $\mathrm{m}^{-2}$ at $3 \mathrm{~m}$ and that of juvenile Porites increased from 1 to 4.6 ind. $\mathrm{m}^{-2}$ at $9 \mathrm{~m}$ after the SD Event. This suggests that these two genera show a higher recovery potential on degraded reefs, a phenomenon also reported in other reef zones, such as Taiwan [45] and Phuket [22].

\subsection{The recovery process and its impacting factors on Xiaodonghai Reef}

The recovery process for a degraded coral reef is always slow and difficult. Many factors, such as changes in environmental conditions [46] and accompanying stresses (e.g. typhoon damage, outbreaks of coral predators and coral disease) [17,46], influence coral reef recovery. Nine months of dredging caused coral cover to decline by $30 \%$ in Phuket, with cover recovering to the former level 13 months after the event [22]. This recovery is attributed to there being no accompanying stresses and the powerful regeneration of surviving dominant massive corals after the dredging event [22]. For example, massive Porites can tolerate sediment deposition through heavy mucous secretion, trapping and subsequent sloughing and regenerate living tissues over formerly dead surfaces $[22,47]$.

No recovery of coral communities was observed on Xiaodonghai Reef 11 months after the SD Event. Indeed, the coral community at $3 \mathrm{~m}$ and $6 \mathrm{~m}$ was in further degradation. This was probably attributable to other disturbances, such as an outbreak of the corallivorous snail Drupella spp. and Typhoon Conson (Figure 5). The mean density of snails after the SD Event (8.6 ind. $\mathrm{m}^{-2}$ ) was higher than values during outbreak (1.4-6.4 ind. $\mathrm{m}^{-2}$ ) [48] and the threshold for having detrimental effects on coral communities $\left(2\right.$ ind. $\left.\mathrm{m}^{-2}\right)$ [49]. The reason for the outbreak of Drupella spp. on Xiaodonghai Reef remains unknown. It is likely that the presence of stressed coral colonies (due to the SD Event) and the absence of snail predators, such as large fishes (e.g. grouper, triggerfish and sharks) and crabs, due to long-term over-fishing [30,31], probably induced the outbreak [50,51]. The snails mainly predated on the dominant coral G. fascicularis (with a percentage composition of 70\%-94.8\% before the SD Event) and together with other disturbances (e.g. typhoon damage and high sedimentation), this predation probably caused the coral G. fascicularis to disappear from the deep water areas of Xiaodonghai Reef (Figure 6(b)-(c)). An outbreak of corallivorous snails and its severe detrimental effect on coral communities, especially on the dominant coral G. fascicularis, has also been reported at Penghu Island [51]. Therefore, this study highlights the importance of regeneration of colonies of dominant corals that have suffered partial mortality due to acute disturbances in promoting reef recovery $[22,52]$.

Juvenile coral density decreased after the SD Event, and this was especially evident for Galaxea. Thus, low coral recruitment $\left(6.4\right.$ ind. $\left.\mathrm{m}^{-2}\right)$ was probably another factor limiting recovery of the coral community on Xiaodonghai Reef. However, the specific reasons for this low coral recruitment, which may include deterioration of suitable habitats or lack of coral larvae, are unknown and should be investigated in the future.

\subsection{Causes of degradation of the coral communities in Yulin Bay from 2008-2010}

Mean live coral cover in Yulin Bay declined from approximately $50 \%$ in 1978 [29] to $33.1 \%$ in 2006 [28] (Figure 9) and the dominant species shifted from branching Acropora spp. to massive species (e.g. Porites lutea and G. fascicularis) $[28,29]$. This shift was in accord with the significant change in coral cover and composition seen during the past few decades on nearby Luhuitou Fringing Reef off Sanya and on Daya Bay Reef off Shenzhen (Figure 9). However, a significant decrease in coral cover of both reef zones was 


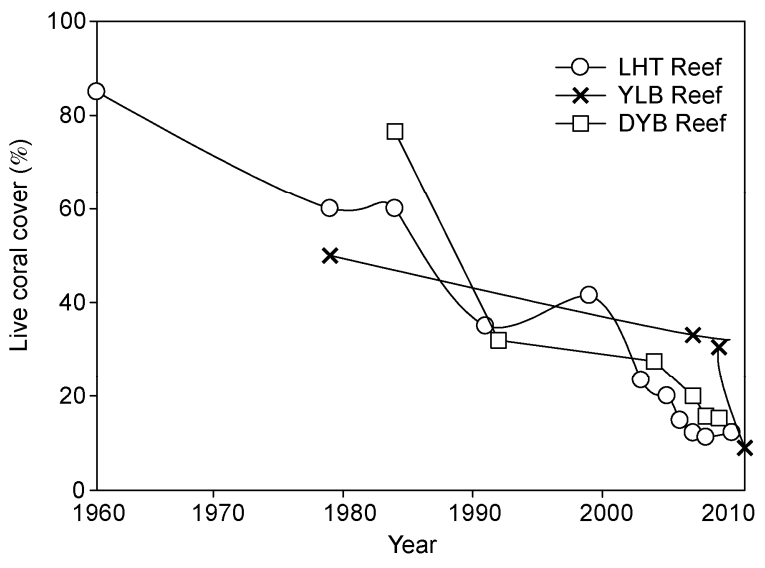

Figure 9 Variation in mean live coral cover in Yulin Bay since 1978 (YLB Reef) (data for 1978 [29]; data for 2006 [28]; data for 2008 and 2010, this article) and variation of mean live coral cover in Luhuitou Fringing Reef (LHT Reef) [55] and Daya Bay Reef (DYB Reef) [54] since 1960 and 1983 , respectively.

observed before 1990, and was related to reef block mining, curio collecting and destructive fishing activities on Luhuitou Fringing Reef [53]. Anthropogenic impacts, such as sediment influx from the construction of the Daya Bay Nuclear Power Station and an oil depot were responsible for the decline of Daya Bay Reef [54]. The causes of the decline in live coral cover in Yulin Bay before 1990 were associated with coral mining, destructive fishing and siltation [30,31], and this was consistent with the situation on Luhuitou Fringing Reef due to their closeness and exposure to similar human activities. Along with the rapid development of economies of Sanya and Shenzhen since 2000, the coastal environments near these cities have gradually changed, resulting in detrimental effects on nearby coral reefs. Mean live coral cover decreased from $14.8 \%$ in 2005 to about $13 \%$ in 2009 on Luhuitou Fringing Reef [55] and from 20\% in 2003 to $15.3 \%$ in 2008 in Daya Bay [54]. The above results suggest that seawater quality degradation may result in gradual changes in live coral cover. However, the dramatic changes in mean live coral cover (from $30.5 \%$ in 2008 to $9 \%$ in 2010), coral community composition (the shift to more tolerant coral species) and mean density of juvenile corals (from 15 ind. $\mathrm{m}^{-2}$ in 2006 [28] to 4.9 ind. $\mathrm{m}^{-2}$ in 2010 [27]) in Yulin Bay over a relatively short time (2-4 years) were probably a consequence of more severe disturbances.

Studies have found that factors which can degrade coral communities in a very short time include coral bleaching due to high thermal stress [4], outbreaks of Acanthaster planci $[7,8]$, typhoon damage $[9,46]$ and high sedimentation events caused by human activities (e.g. dredging and sediment dumping) [22,23]. Time-series measurements of seawater temperature showed that no extremely high seawater temperature was observed during the course of the present study and that the hottest month seawater temperature between 2008 and 2010 in Yulin Bay was lower than the coral bleaching threshold of Hainan Island suggested by NOAA
Coral Reef Watch $\left(30.2^{\circ} \mathrm{C}\right.$; Figure 1). Field surveys also indicated that no coral bleaching due to high thermal stress was recorded from 2008-2009 in the Sanya National Natural Coral Reef Reserve. However, slight coral bleaching was observed on Luhuitou Fringing Reef [56] and some other reef areas, such as Xidao (Sanya Bay) and Yezhudao (Yalong Bay) in 2010. Most bleached coral colonies eventually recovered after the bleaching event [56]. The mean density of Acanthaster planci was 0.3 ind. $300 \mathrm{~m}^{-2}$, ranging from 0 to 1 ind. $300 \mathrm{~m}^{-2}$ at YL2, YL4 and YL6 in November 2010 (Li et al., unpublished data). This figure was lower than the threshold of an outbreak of Acanthaster planci (1.2 ind. $300 \mathrm{~m}^{-2}$ ) [8]. One typhoon (Conson) landed in Sanya on 16 July, 2010 and had detrimental effects on nearby coral communities. Field surveys showed that the reefs which were severely impacted by Typhoon Conson were those where the dominant coral forms were branching and foliaceous, such as Yezhudao. Subsequent monitoring confirmed the complete recovery of the coral community at Yezhudao one year later ( $\mathrm{Li}$ et al., unpublished data). However, the coral communities of Yulin Bay have been mainly composed of massive corals since 2008 and coral bleaching, Acanthaster planci predation and typhoon damage therefore appeared to play minor roles in the degradation seen between 2008 and 2010.

However, a large amount of silt-clay-sized sediment, rich with organic matter $(8.4 \% \pm 1.0 \%$, ranging from $7.1 \%$ to 9.7\%) [27], was observed on coral reefs in Yulin Bay in 2010 after the SD Event (Figure 3(d)). A recent study showed that sedimentation kills corals through microbial processes triggered by the organic matter in the sediments [57]. The fine and organic sediment showed higher potential detrimental effects on coral communities [58]. In Yulin Bay, dead or partially dead coral colonies induced by sediment burial and tissue necrosis were seen after the SD Event (Figure 3). And coral communities also shifted to species more tolerant of high sedimentation between 2008 and 2010. Therefore, high sedimentation appears to have played a major role in the degradation of coral communities in Yulin Bay from 2008-2010. Moreover, significant changes in the coral community on Xaodonghai Reef after the SD Event, together with heavy sedimentation and strong light shading during the SD Event (Figure 4), provide more direct evidence on the detrimental effect of high sedimentation on the coral communities in Yulin Bay. We therefore concluded that the rapid coral community degradation in Yulin Bay between 2008 and 2010 was probably caused by high sediment deposition induced by dredging and sediment dumping, or soil erosion from land clearing during the rainy seasons (Figure 3(c)).

\section{Conclusions}

This is the first study to show that dredging and sediment 
dumping caused significant degradation of coral communities in mainland China. The responses of coral communities on Xiaodonghai Reef to the SD Event differed depending upon the distribution depth and the coral community composition. Coral communities at $3 \mathrm{~m}$ suffered less impact than those at deeper depths. At 6 and $9 \mathrm{~m}$, the coral $D$. heliopora showed higher tolerance to heavy sedimentation than the dominant coral G. fascicularis. Based on coral community change and the sediment accumulation rate on Xiaodonghai Reef, our results suggest that the threshold of D. heliopora was more than $36 \mathrm{mg} \mathrm{cm}^{-2} \mathrm{~d}^{-1}$ while the threshold of $G$. fascicularis was lower, being close to 19.1 $\mathrm{mg} \mathrm{cm} \mathrm{c}^{-2}$ when exposed to high sedimentation for 2-3 months. Because of the accompanying disturbances, such as Typhoon Conson and an outbreak of the corallivorous snail Drupella spp, the coral community of Xiaodonghai Reef went into further decline after the SD Event.

This study also confirmed the severe degradation of coral communities in Yulin Bay from 2008-2010, which was probably caused by high sediment deposition as a result of intensive dredging and land-clearing activities. Therefore, heavy sedimentation, together with the sewage pollution from Hongsha Port and the Liudao city sewage outlet, has become the main threat to coral communities in Yulin Bay. With the rapid development of harbor construction and coast development around the world, an integrated watershed management is needed to control sediment deposition and soil erosion around near-shore coral reefs. Using Yulin Bay as an example, land clearing and dredging activities should be conducted only during the dry season to avoid soil erosion through rainwater [59]. The dredged sediment should then be dumped cautiously, for example in the area beyond Yinggebi or Jinmujiao on ebb tides.

The authors thank the editors and the two anonymous reviewers for their valuable comments on the manuscript. This work was supported by Key Topics in Innovation Engineering of the Chinese Academy of Sciences (KZCX2-YW-227), the National Natural Science Foundation of China (40830850, 41106141 and 40931160437), the National Key Technology $R \& D$ Program (2009BAB44B01) and the Ocean Public Welfare Scientific Research Project (201005012-6).

1 Moberg F, Folke C. Ecological goods and services of coral reef ecosystems. Ecol Econ, 1999, 29: 215-233

2 Wilkinson C. Status of coral reefs of the world: 2008. Global Coral Reef Monitoring Network and Reef and Rainforest Research Centre, Townsville, Australia, 2008. 1-296

3 Carpenter K E, Abrar M, Aeby G, et al. One-third of reef-building corals face elevated extinction risk from climate change and local impacts. Science, 2008, 321: 560-563

4 Hoegh-Guldberg O. Climate change, coral bleaching and the future of the world's coral reefs. Mar Freshwater Res, 1999, 50: 839-866

5 Li S, Yu K F, Chen T R, et al. Assessment of coral bleaching using symbiotic zooxanthellae density and satellite remote sensing data in the Nansha Islands, South China Sea. Chin Sci Bull, 2011, 56: 10311037

6 Hoegh-Guldberg O, Mumby P J, Hooten A J, et al. Coral reefs under rapid climate change and ocean acidification. Science, 2007, 318: 1737-1742
7 Pratchett M S, Schenk T J, Baine M, et al. Selective coral mortality associated with outbreaks of Acanthaster planci in Bootless Bay, Papua New Guinea. Mar Environ Res, 2009, 67: 230-236

8 Pratchett M S. Changes in coral assemblages during an outbreak of Acanthaster planci at Lizard Island, northern Great Barrier Reef (1995-1999). Coral Reefs, 2010, 29: 717-725

9 Hughes T P. Catastrophes, phase shifts, and large-scale degradation of a Caribbean coral reef. Science, 1994, 265: 1547-1551

10 Fabricius K E. Effects of terrestrial runoff on the ecology of corals and coral reefs: Review and synthesis. Mar Pollut Bull, 2005, 50: 125-146

11 Fabricius K E. Factors determining the resilience of coral reefs to eutrophication: A review and conceptual model. In: Dubinsky Z, Stambler N, eds. Coral Reefs: An Ecosystem in Transition. Berlin: Springer, 2011. 493-505

12 Xing S, Tan Y H, Zhou L B, et al. Effects of water turbidity on the symbiotic zooxanthella of hermatypic corals (in Chinese). Chin Sci Bull (Chin Ver), 2012, 57: 348-354

13 Hodgson G. Tetracycline reduces sedimentation damage to corals. Mar Biol, 1990, 104: 493-496

14 Staffordsmith M G. Sediment-rejection efficiency of 22 species of Australian scleractinian corals. Mar Biol, 1993, 115: 229-243

15 Fabricius K E, Cooper T F, Humphrey C, et al. A bioindicator system for water quality on inshore coral reefs of the Great Barrier Reef. Mar Pollut Bull, 2011, 65: 320-332

16 Van Woesik R, Tomascik T, Blake S. Coral assemblages and physico-chemical characteristics of the Whitsunday Islands: Evidence of recent community changes. Mar Freshwater Res, 1999, 50: 427440

17 Rogers C S. Responses of coral reefs and reef organisms to sedimentation. Mar Ecol Prog Ser, 1990, 62: 185-202

18 Erftemeijer P L, Riegl B, Hoeksema B W, et al. Environmental impacts of dredging and other sediment disturbances on corals: A review. Mar Pollut Bull, 2012, 64: 1737-1765

19 Sofonia J J, Unsworth R K F. Development of water quality thresholds during dredging for the protection of benthic primary producer habitats. J Environ Monitor, 2010, 12: 159-163

20 Maragos J E. A study of the ecology of Hawaiian reef corals. Dissertation for the Doctoral Degree. Honolulu: University of Hawaii, 1972. $1-580$

21 Uchino K. Long-term ecological impacts of dredging on coral reefs in Kaneohe Bay. Dissertation for the Master Degree. Manoa: University of Hawaii, 2004. 1-82

22 Brown B E, Letissier M D A, Scoffin T P, et al. Evaluation of the environmental impact of dredging on intertidal coral reefs at Ko Phuket, Thailand, using ecological and physiological parameters. Mar Ecol Prog Ser, 1990, 65: 273-281

23 Morton B. Hong Kong's coral communities: Status, threats and management plans. Mar Pollut Bull, 1994, 29: 74-83

24 Pastorok R A, Bilyard G R. Effects of sewage pollution on coral reef communities. Mar Ecol Prog Ser, 1985, 21: 175-189

25 Che Z W. Assessment and preventive countermeasures for eutrophication status of Yulin Bay (in Chinese). J Hainan Norm Univ (Nat Sci), 2006, 19: 362-365

26 Wu G W. Survey and preliminary study of the status quo of marine ecology of Liudao Bay in Sanya (in Chinese). J Hainan Norm Univ (Nat Sci), 2005, 18: 66-70

27 Li X B. Identification of major factors influencing the composition, spatial and temporal variation of scleractinian coral community in Sanya, China (in Chinese). Dissertation for the Doctoral Degree. Beijing: Chinese Academy of Sciences. 2011. 1-107

28 Lian J S, Huang H. Sanya Coral Reefs and their Biodiversity (in Chinese). Beijing: China Ocean Press, 2010. 1-106

29 Wang G Z. Sedimentology of the Coral Reefs in the South China Sea (in Chinese). Beijing: China Ocean Press, 2001. 1-313

30 Hutchings P A, Wu B L. Coral reefs of Hainan Island, South China Sea. Mar Pollut Bull, 1987, 18: 25-26

31 Fiege D, Neumann V, Li J H. Observations on coral reefs of Hainan Island, South China Sea. Mar Pollut Bull, 1994, 29: 84-89 
32 Chen Z S. Gulf Chi of China Volume 11 (Hainan Gulf) (in Chinese). Beijing: China Ocean Press, 1999. 1-409

33 Guan W B, Won G L, Pan J M, et al. Application of the Princeton Ocean Model to investigating pollutant transport in a firth (in Chinese). Acta Oceanol Sin, 2002, 24: 9-17

34 Yentsch C S, Yentsch C M, Cullen J J, et al. Sunlight and water transparency: Cornerstones in coral research. J Exp Mar Biol Ecol, 2002, 268: 171-183

35 Nadon M O, Stirling G. Field and simulation analyses of visual methods for sampling coral cover. Coral Reefs, 2006, 25: 177-185

36 Edmunds P J, Aronson R B, Swanson D W, et al. Photographic versus visual census techniques for the quantification of juvenile corals. Bull Mar Sci, 1998, 62: 937-946

37 Guillemot N, Chabanet P, Le Pape O. Cyclone effects on coral reef habitats in New Caledonia (South Pacific). Coral Reefs, 2010, 29: $445-453$

38 Staffordsmith M G, Ormond R F G. Sediment-rejection mechanisms of 42 species of Australian scleractinian corals. Aust J Mar Fresh Res, 1992, 43: 683-705

39 Rogers C S. Effect of shading on coral reef structure and function. J Exp Mar Biol Ecol, 1979, 41: 269-288

40 Roder C, Jantzen C, Schmidt G M, et al. Metabolic plasticity of the corals Porites lutea and Diploastrea heliopora exposed to large amplitude internal waves. Coral Reefs, 2011, 30: 57-69

41 Fabricius K E, Golbuu Y, Victor S. Selective mortality in coastal reef organisms from an acute sedimentation event. Coral Reefs, 2007, 26: 69-69

42 Philipp E, Fabricius K. Photophysiological stress in scleractinian corals in response to short-term sedimentation. J Exp Mar Biol Ecol, 2003, 287: 57-78

43 Dutra L X C, Kikuchi R K P, Leao Z M A N. Effects of sediment accumulation on reef corals from Abrolhos, Bahia, Brazil. J Coastal Res, 2006, 2: 633-638

44 Fabricius K E, Wild C, Wolanski E, et al. Effects of transparent exopolymer particles and muddy terrigenous sediments on the survival of hard coral recruits. Estuar Coast Shelf S, 2003, 57: 613-621

45 Kuo K M, Soong K. Post-settlement survival of reef-coral juveniles in southern Taiwan. Zool Stud, 2010, 49: 724-734

46 Connell J H. Disturbance and recovery of coral assemblages. Coral Reefs, 1997, 16: S101-S113

47 Dikou A, Van Woesik R. Survival under chronic stress from sediment load: Spatial patterns of hard coral communities in the southern Islands of Singapore. Mar Pollut Bull, 2006, 52: 1340-1354

48 Cumming R L. Population outbreaks and large aggregations of Drupella on the Great Barrier Reef. Townsville, Australia: The Great Barrier Reef Marine Park Authority Report, 2009. 1-22

49 Morton B, Blackmore G. Seasonal variations in the density of and corallivory by Drupella rugosa and Cronia margariticola (Caenogastropoda: Muricidae) from the coastal waters of Hong Kong: "plagues" or "aggregations"? J Mar Biol Assoc UK, 2009, 89: 147-159

50 Shafir S, Gur O, Rinkevich B. A Drupella cornus outbreak in the northern Gulf of Eilat and changes in coral prey. Coral Reefs, 2008, 27: 379

51 Chen C L A, Hsieh H Y J, Chen K S, et al. Establishment of a notake area (NTA) could not guarantee the preservation of coral communities in Chinwan Inner Bay, Penghu, Taiwan. Zool Stud, 2011, 50: 443-453

52 Diaz-Pulido G, Mccook L J, Dove S, et al. Doom and boom on a resilient reef: Climate change, algal overgrowth and coral recovery. PLoS One, 2009, 4: e5239, doi: 10.1371/journal.pone.0005239

53 Zhang Q M, Shi Q, Chen G, et al. Status monitoring and health assessment of Luhuitou Fringing Reef of Sanya, Hainan, China. Chin Sci Bull, 2006, 51: 81-88

54 Chen T R, Yu K F, Shi Q, et al. Twenty-five years of change in scleractinian coral communities of Daya Bay (northern South China Sea) and its response to the $2008 \mathrm{AD}$ extreme cold climate event. Chin Sci Bull, 2009, 54: 2107-2117

55 Zhao M X, Yu K F, Zhang Q M, et al. Long-term dynamics of coral cover in Luhuitou Fringing Reef, Sanya (in Chinese). Oceanol Limnol Sin, 2010, 6: 440-447

56 Li X. B., Liu S, Huang H, et al. Coral bleaching caused by abnormal water temperature rise in Luhuitou Fringing Reef of Sanya Bay, China. Aquat Ecosyst Health, 2012, 15: 227-233

57 Weber M, De Beer D, Lott C, et al. Mechanisms of damage to corals exposed to sedimentation. Proc Natl Acad Sci USA, 2012, 109: E1558-1567

58 Weber M, Lott C, Fabricius K E. Sedimentation stress in a scleractinian coral exposed to terrestrial and marine sediments with contrasting physical, organic and geochemical properties. J Exp Mar Biol Ecol, 2006, 336: 18-32

59 Wilkinson C, Brodie J. Catchment Management and Coral Reef Conservation: A practical guide for coastal resource managers to reduce damage from catchment areas based on best practice case studies. Global Coral Reef Monitoring Network and Reef and Rainforest Research Centre Townsville, Australia, 2011. 1-120

Open Access This article is distributed under the terms of the Creative Commons Attribution License which permits any use, distribution, and reproduction in any medium, provided the original author(s) and source are credited. 